\title{
Research on the Application of WeChat Supported PBL in English Teaching of Basic Chemistry for Higher Medical Education for International Medical Students
}

\author{
Xianjiu Liao, Yan Li, Li Qian, Suoyi Huang, Xiufeng Huang, Yan-E Zhou, Qianli Tang* \\ Youjiang Medical University for Nationalities, Baise, China \\ Email: ^htmgx919@163.com
}

How to cite this paper: Liao, X. J., Li, Y., Qian, L., Huang, S. Y., Huang, X. F., Zhou, Y.-E, \& Tang, Q. L. (2020). Research on the Application of WeChat Supported PBL in English Teaching of Basic Chemistry for Higher Medical Education for International Medical Students. Creative Education, 11, 1690-1696.

https://doi.org/10.4236/ce.2020.119123

Received: August 21, 2020

Accepted: September 15, 2020

Published: September 18, 2020

Copyright $\odot 2020$ by author(s) and Scientific Research Publishing Inc. This work is licensed under the Creative Commons Attribution International License (CC BY 4.0).

http://creativecommons.org/licenses/by/4.0/

\begin{abstract}
Objective: To construct a WeChat supported PBL teaching mode, apply it in the lecturing on Basic Chemistry for Higher Medical Education, and explore its teaching effect. Methods: We selected the international students enrolled in 2014 and 2015 as teaching objects, who were divided at random into the control group and experimental group, with the students in experimental group taught in the WeChat supported PBL teaching mode, and those in control group in the traditional mode. Upon the completion of teaching, the students' learning experience in the new teaching mode was investigated, and their final results in Basic Chemistry for Higher Medical Education were compared. Results: The students in experimental group were satisfied with their learning experience in the new teaching mode and learning effect therefrom; their final scores of Basic Chemistry for Higher Medical Education were also higher than those of the students in the control group. Conclusion: WeChat supported PBL teaching mode, with its emphasis on the in-depth integration between information technology and curriculum, helps improve students' interest and initiatives in independent learning, promote timely communication between teachers and students, and improve the comprehensive ability of international students, which is worthy of optimization and promotion in teaching.
\end{abstract}

\section{Keywords}

PBL, International Medical Students, Medical Chemistry, Mobile Learning, Information Technology 


\section{Introduction}

At present, since the number of international medical students in China ranks No. 2 among the international students of different specialties, the teaching for them has become an important part of education in the medical colleges. Most of the international medical students in Youjiang Medical University for Nationalities come from such countries and regions as Pakistan, whose learning modes and thinking patterns greatly differ from those of domestic students. Basic chemistry for higher medical education, as an important elementary course in clinical medicine, focuses both on the classic theoretical system in chemistry and on the construction of scientific thinking while the medical education for international students. With its close correlation with the medical sciences, teaching effect of the discipline has a direct impact on the overall evaluation on the teaching effect for international students. Basic chemistry for higher medical education is featured with its complicated and massive contents, lack of logics, extensive interdisciplines, dull learning process, confusing knowledge points and difficulty in remembering and teaching (Guo, Cui, Dong, \& Li, 2020).

Problem-based learning $(\mathrm{PBL})$ is a student-centered education mode in real contexts. Its introduction of students into cases of problems, teacher-student/ student-student communication, dialogue, study, discussion and other methods stimulates students' interest in learning, cultivates their ability to analyze and solve problems, and improves their creative ability (Tang \& Zhang, 2019).

In the era of "Internet plus Education", we should promote the integration between information technology and course education, improve teachers' application of information technology, reform existing classroom teaching modes, and provide students with rich and colorful educational environment and learning tools (Ni, Li, \& Huang, 2019). WeChat is an APP characterized by transmission of voice, video, picture and text, group chat and real-time communication. With its popularity among the college students, it is more and more extensively used in teaching of different disciplines and universities, providing a platform to teachers and students to communicate and learn together (Wang, 2020). Thanks to the great popularity of WeChat among the international students in Youjiang Medical University for Nationalities, we explored to use and take it as the PBL teaching platform and the carrier of case teaching in the teaching reform and innovation.

\section{Research Objects and Methods}

\subsection{Research Objects}

We selected the international students enrolled in 2014 and 2015 by Youjiang Medical University for Nationalities as the research objects, with Grade 2014 as experimental group (80 students) and Grade 2015 as control group (50 students). The basic chemistry for higher medical education for both groups is carried out for 30 credit hours, with Basic Chemistry for Higher Medical Education 
(Edition II, People's Medical Publishing House) by Wei Zuqi and Fu Ying. Basic conditions of students in the two groups, including sex, age and basics, etc., were comparable.

\subsection{Research Methods}

Based on the traditional teaching, the experimental group constructed WeChat Teaching Platform, and received the mobile PBL teaching of some representative chapters in combination with the curricular characteristics of basic chemistry for higher medical education. We prepared cases closely correlated with basic chemistry for higher medical education before the class, and forwarded such cases via WeChat, so that students could analyze them after class. We required students to find corresponding information to the cases, cooperate in teams, and interact with each other via WeChat. While teaching, the teachers elaborated the cases, and instructed on the group discussion; then, the teachers discussed with the student discuss. After class, teachers communicated with students via WeChat to help students solve problems and improve teaching content. The control group was educated in the traditional teaching mode.

\subsection{Effectiveness Evaluation}

We selected 36 students at random for investigation and research, and the students were required to evaluate the learning effect from WeChat supported PBL teaching mode. The investigation involves mobilization of learning enthusiasm, improvement of interest in learning, assistance in the extension of classroom teaching, facilitation of the timely communication between teachers and students, improvement of the ability in judgment and knowledge application, improvement of comprehensive ability, etc.

\subsection{Statistical Results}

SPSS22.0 software was employed in the data analysis. The enumeration data is represented with $\mathrm{n}(\%)$, and the measurement data with $(\bar{x} \pm s)$. T-test was conducted as per the normal distribution. The difference was statistically significant with $P<0.05$.

\section{Results}

\subsection{Learning Experience of Experimental Group Students}

In the era of "Internet plus Education", teachers can use the Internet teaching platform and traditional teaching modes to provide students with rich independent learning resources, thereby improving students' learning experience. According to the investigation results (Table 1), the average satisfaction rate among the students in experimental class for the "WeChat + $\mathrm{PBL}$ " teaching mode was $83.80 \%$, indicating "WeChat $+\mathrm{PBL}$ " teaching mode facilitated the interaction between teachers and students in a more effective manner, help expand the classroom teaching, improved their learning interest. 


\subsection{Performance Comparison in the Control Group and Experimental Group}

We explore the influence of two teaching methods on students' performance based on the comparison of their final examination results and comprehensive performance; wherein, final comprehensive performance $=$ usual performance $(30 \%)+$ final examination result $(70 \%)$. The final examination result in the experimental group was $(94.99 \pm 3.912)$ with a comprehensive performance of $(92.04 \pm 2.941)$ at a pass rate of $100 \%$; the final examination result in the control group was $(90.10 \pm 6.991)$ with a comprehensive performance of ( $88.57 \pm 5.413)$. According to the results, the final result and comprehensive performance of the experimental group were better than those of the control group, whose difference was statistically significant $(P<0.05)$ (Table 2$)$.

\section{Discussion}

PBL teaching mode differs from the traditional "cramming" teaching modes completely because it is problem-based, student-centered, and teacher-guided, which is aimed to encourage students to take the initiatives in thinking, consulting literatures, proposing questions and carrying out corresponding discussions (Sun, $\mathrm{Hu}$, Chen, $\mathrm{Hu}, \& \mathrm{Li}, 2020$ ). Real-time and interactive WeChat can establish a communication platform between teachers and students anywhen and anywhere, and help implement PBL teaching mode. "WeChat + PBL" teaching method is aimed to implement the teaching reform and innovation, with WeChat as the carrier of case teaching:

1) "WeChat + PBL" mode improved the interest and enthusiasm in independent learning

Table 1. Learning experience of students in the experimental group (\%).

\begin{tabular}{ccc}
\hline Survey items & Satisfied & Mediocre \\
\hline Mobilization of learning enthusiasm & 83.33 & 16.67 \\
Improvement of interest in learning & 83.33 & 16.67 \\
Assistance in the extension of classroom teaching & 80.56 & 19.44 \\
Facilitation of the timely communication between teachers and students & 88.89 & 11.11 \\
Improvement of the ability in judgment and knowledge application & 80.56 & 19.44 \\
Improvement of comprehensive ability & 86.11 & 13.89 \\
Total average score & 83.80 & 16.20 \\
\hline
\end{tabular}

Table 2. Comparison of academic performance between the experimental group and the control group $(\bar{x} \pm s)$.

\begin{tabular}{cccc}
\hline Group & Number of students & Final result & Comprehensive performance \\
\hline Experimental group & 80 & $94.99 \pm 3.912$ & $92.04 \pm 2.941$ \\
Control group & 50 & $90.10 \pm 6.991$ & $88.57 \pm 5.413$ \\
$t$ & & 4.521 & 4.163 \\
$P$ & $<0.01$ & $<0.01$ \\
\hline
\end{tabular}


Chemistry, as a central discipline, has a profound impact on the research and development of medicine. Nevertheless, the medical students can hardly be aware of the importance of basic chemistry to medical courses in traditional textbooks. In the basic chemistry teaching mode of "WeChat + PBL", we selected some representative chapters and applied basic chemistry in clinical cases to enrich classroom teaching and stimulate students' interest and enthusiasm in independent learning better. For example, during the presentation of "Coordination Compound", we prepared the cases as follows: What is the pathogenesis of gas poisoning? What is the mechanism of heavy metal poisoning \& detoxification? What is the anticancer mechanism in coordination compounds? Teachers forwarded the cases to students via WeChat, so that students could take the initiatives in consulting literatures and preparing answers. The international students actively discussed via WeChat to deepen their understanding of coordination compounds based on the analysis of cases. By such means, the basic chemistry teaching mode of "WeChat + PBL" made the abstract and boring knowledge points in textbooks more vivid and correlated with clinical application, which greatly improved their interest and initiatives in learning basic chemistry. According to the investigation results, $83.33 \%$ of the international students in the experimental group thought that the new teaching mode could stimulate their learning enthusiasm; $83.33 \%$ of them thought that the new teaching mode could improve their learning interest.

2) "WeChat + PBL" mode promoted timely communication between teachers and students

While teaching, we found that most of the international students, subject to the influence of western civilization, prefer a free and open-up teaching environment where they can take the initiative in questioning and answering. They enjoy communicating and discussing with their teachers. The traditional teaching mode, due to its tempo-spatial restrictions, can only impart limited knowledge in class, and the students' assimilation of knowledge is passive, and short of communication; students cannot take the initiatives in thinking or achieve better emotional communication with each other/with teachers, which is not conducive to the feedback of teaching information ( $\mathrm{Mu}$, Dong, Tang, \& Zhou, 2019). "WeChat + PBL" mode, based on WeChat, can forward teaching resources to international students, which makes learning "everywhere and anywhen". As a matter of fact, it expands the teaching classroom for the international students. "WeChat + PBL" mode also allows students to discuss freely while learning, reduces the teachers' abstract expression, and facilitates timely communication and feedback, enhances the attachment between teachers and students, transforms students from "passive learning" to "active learning", and consolidates the dominant position of students. According to the investigation results, $80.56 \%$ of the international students in the experimental class thought that "WeChat + PBL" mode was conducive to the expansion of classroom teaching; $88.89 \%$ believed that "WeChat + PBL" mode facilitated the timely communication between teachers and students. 
3) "Wechat + PBL" mode helps improve students' comprehensive ability

The new teaching mode changes the "teacher-centered" teaching concept, constructs a "student-centered" teaching concept, establishes an idea of cooperative teaching between teachers and students, gives more emphasis to the development of students' comprehensive ability, and facilitates students' sustainable development. In the traditional classroom, students tend to learn the basic knowledge of chemistry, which is rarely correlated with clinical application. However, in the WeChat supported PBL teaching mode, students must consult various literatures and learning materials after class to complete the classroom discussion, which cultivates their ability in information acquisition, self-learning and teamwork. Multiple discussions cultivate their ability in communication and thinking, which improves their comprehensive quality (Sun, Du, \& Zhou, 2020). According to the investigation results, $80.56 \%$ of the international students in the experimental class believe that "WeChat $+\mathrm{PBL}$ " mode could improve their ability in judgment and knowledge application; $86.11 \%$ of them believed that "WeChat $+\mathrm{PBL}$ " mode helped improve their comprehensive ability.

\section{Conclusion}

In the era of "Internet plus Education", we should promote the integration between information technology and course education, update the teaching concepts, reform existing classroom teaching modes, and provide students with rich and colorful educational environment and learning tools. "WeChat + PBL" mode promoted the development of ubiquitous learning and mobile learning, making learning "everywhere and anywhen". International students, characterized by strong subjective initiatives and active thinking pattern, can adapt to "WeChat + PBL" mode especially. Before class, we forwarded learning materials via WeChat to trigger discussions; they would discuss relevant topics during the class under the teachers' guidance; after class, they would continue the communication via WeChat. "Wechat + PBL" mode has transformed from the traditional "teacher-centered" concept to the "student-centered" concept; with more emphasis on the in-depth integration between information technology and curriculum, the mode helps improve students' interest and initiatives in independent learning, promote timely communication between teachers and students, and improve the comprehensive ability of international students, which is worthy of optimization and promotion in teaching.

\section{Fund Program}

Subject of Guangxi Educational Science in the $13^{\text {th }}$ Five-year Planning + "Research on the Application of WeChat Supported PBL in English Teaching of Elementary Medical Chemistry for International Medical Students" + (2017C403).

\section{Conflicts of Interest}

The authors declare no conflicts of interest regarding the publication of this paper. 


\section{References}

Guo, W., Cui, L., Dong, L., \& Li, X. R. (2020). Blended Teaching Practice of Medical Chemistry for International Students Majoring in Clinical Medicine. Basic Medical Education, 22, 210-212.

Tang, G., \& Zhang, L. (2019). Application of CBL-Based and PBL-Aided Teaching Mode in Clinical Teaching of Nephrology in Traditional Chinese Medicine. Journal of Youjiang Medical University for Nationalities, 41, 708-709 + 712.

Ni, A. N., Li, G. L., \& Huang, X. M. (2019). Application of Grouping Micro-Video Competition Mode in Large-Class Biochemistry Teaching. Journal of Youjiang Medical University for Nationalities, 41, 222-224.

Wang, H. M. (2020). Application of WeChat-Based Medical Laboratory Teaching. China Continuing Medical Education, 12, 35-37.

Sun, Y. X., Hu, Z. W., Chen, X. L., Hu, D. L., \& Li, X. Z. (2020). Discussion on the "Student-Centered" Concept in Large-class Medical Teaching. Journal of Youjiang Medical University for Nationalities, 42, 252-254 + 264 .

Mu, S., Dong, J., Tang, D. M., \& Zhou, Y. J. (2019). Influence of Teacher Behavior on Students' Activities in Information-Based Classroom Teaching. China Educational Technology, No. 8, 91-98.

Sun, L. J., Du, H. J., \& Zhou, J. (2020). Application of WeChat-Based PBL and TBL Teaching Mode in Ophthalmic Probation Teaching. China Medical Education Technology, 34, 214-216 + 220. 